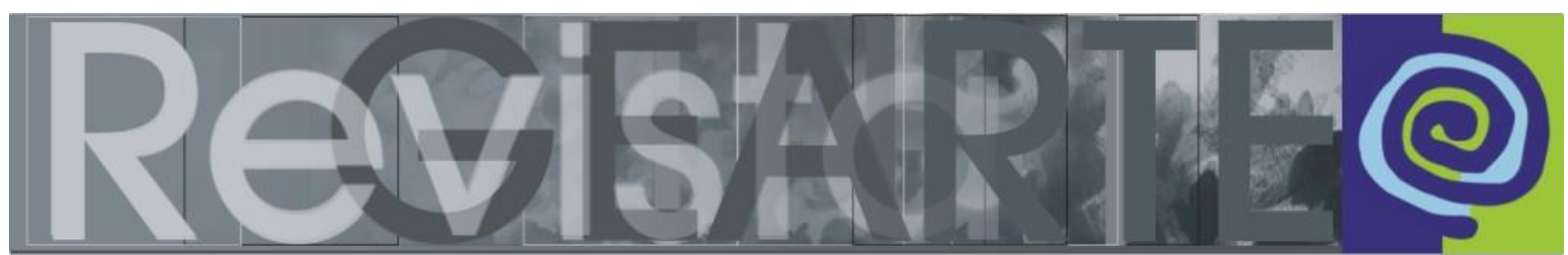

e-ISSN 2357-9854

\title{
Imaginário, subjetividade e tecnologia na formação docente em artes visuais
}

\author{
Cláudia Mariza Mattos Brandão \\ (Universidade Federal de Pelotas — UFPEL, Pelotas/RS, Brasil) \\ Cláudio Tarouco de Azevedo \\ (Universidade Federal de Pelotas — UFPEL, Pelotas/RS, Brasil)
}

\begin{abstract}
RESUMO - Imaginário, subjetividade e tecnologia na formação docente em artes visuais - A influência e o impacto do desenvolvimento tecnológico sobre as pessoas do século XXI atestam a importância de discussões versando sobre o assunto no âmbito da educação. Amparado principalmente em Gilbert Durand e Félix Guattari, o artigo problematiza as mudanças operadas na ordem visual, processadas nos jogos técnicos que originam as imagens, suas reverberações nas subjetividades e os processos educativos, colocando em jogo os mecanismos perceptivos e o envolvimento dos espectadores no campo de intercâmbio constituído pelas imagens. Sendo assim, o texto visa refletir sobre o impacto da tecnologia sobre a vida em sociedade e o papel fundamental da educação, não somente como possibilidade de capacitação a práticas técnicas, mas, principalmente, como utilização dos novos meios em atividades expressivas e reflexivas, de produção de subjetividade, abordando práticas pedagógicas vinculadas à formação docente em Artes Visuais e seus resultados.

PALAVRAS-CHAVE

Artes Visuais. Tecnologias Contemporâneas. Imaginário. Subjetividade. Formação Docente.
\end{abstract}

ABSTRACT - Imaginary, subjectivity and technology in teacher training in the visual arts - The influence and impact of technological development on people of the 21st century attest to the importance of discussions on the subject in education. Mainly supported in Gilbert Durand and Felix Guattari, the article problematizes the changes operated in the visual order, processed in the technical games that originate images, their reverberations in subjectivities and education processes, putting in game the perceptual mechanisms and the involvement of the spectators in the field of exchange constituted by the images. Therefore, the text aims to reflect about the impact of technology on life in society and the fundamental role of education, not only as a possibility of capacity to technical practices, but mainly in the use of new media in expressive and reflexive activities, of subjectivity production, addressing pedagogical practices linked to teacher training in Visual Arts and their results.

KEY WORDS

Visual Arts. Contemporary Technologies. Imaginary. Subjectivity. Teacher Training.

\section{Introdução}

Múltiplos fatores históricos, sociais e culturais contribuíram para o estado atual de mecanização e automatização dos processos de reprodução das imagens. Com isso estabeleceram-se novas relações entre a subjetividade e os automatismos maquínicos, além de hábitos culturais diferenciados (COUCHOT, 2003). desenvolvimento da fotografia, em meados do século XIX, e do cinema, no final do 


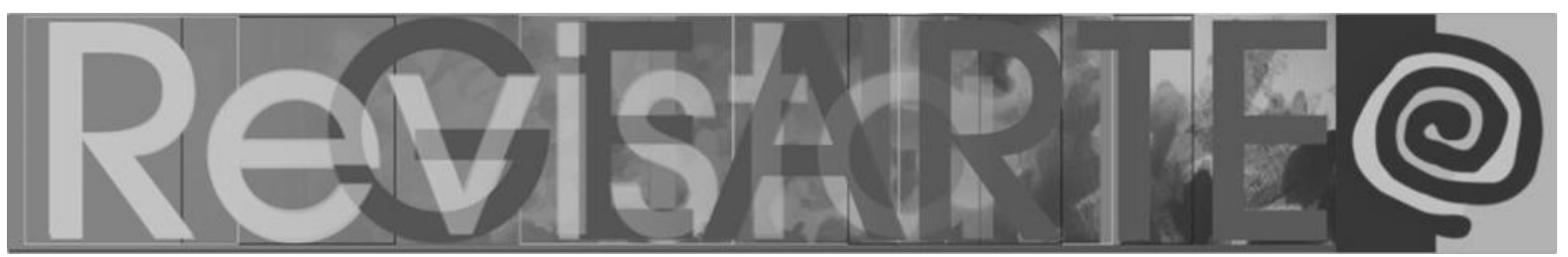

mesmo século, sacramentou tecnologias que passaram a agir amplamente sobre o imaginário social, impondo uma lógica pseudorealista à percepção do mundo. Tais recursos, seus equipamentos, processos e produtos, conquistaram as pessoas e, de certo modo, foram ao longo dos anos modelando os olhares:

Com a fotografia, a presença do objeto se torna incontornável. O objeto preexiste necessariamente à imagem. O real faz pressão sobre a imagem e sua exaltação realista ou seu distanciamento com o simbolismo se torna apenas preocupação do fotógrafo (COUCHOT, 2003, p. 36).

O desenvolvimento tecnológico, seus recursos e reverberações sobre as pessoas e o mundo, faz o século XXI afirmar-se, principalmente, como o século das imagens que atestam presença. Isso invadiu o cotidiano das sociedades contemporâneas através das redes sociais, meios perfeitos para a insaciável vontade humana de revelar-se ao mundo enquanto aparência, num contínuo prazer visual sistematizando personas, idealizadas por egos inflados e saturados de si. Logo, fica clara a importância de discussões versando sobre as tecnologias, práticas, produtos e consequências sobre a formação humana, no âmbito da educação em todos os níveis.

Neste artigo problematizarmos as mudanças operadas na ordem visual, processadas nos jogos técnicos que originam as imagens, suas reverberações nas subjetividades e os processos educativos. Isso, pois colocando em jogo os mecanismos perceptivos "o uso das técnicas conforma cada um segundo um modelo perceptivo partilhado por todos - um habitus comum sobre qual se elabora uma cultura e da qual a arte se alimenta" (COUCHOT, 2003, p. 16). Na análise da situação, consideramos o envolvimento dos espectadores num campo de intercâmbio constituído pelas imagens em sua recepção e suas participações conscientes nesse "jogo", através da capacidade humana de distanciamento perspectivo com relação ao meio (LOPEZ-QUINTÁS, 1992). Entretanto, isso precisa ser privilegiado pelos processos educativos para que qualquer pessoa seja capaz de captar os meandros da(s) realidade(s), participando ativamente da formação da vida cultural através da ação criativa. 


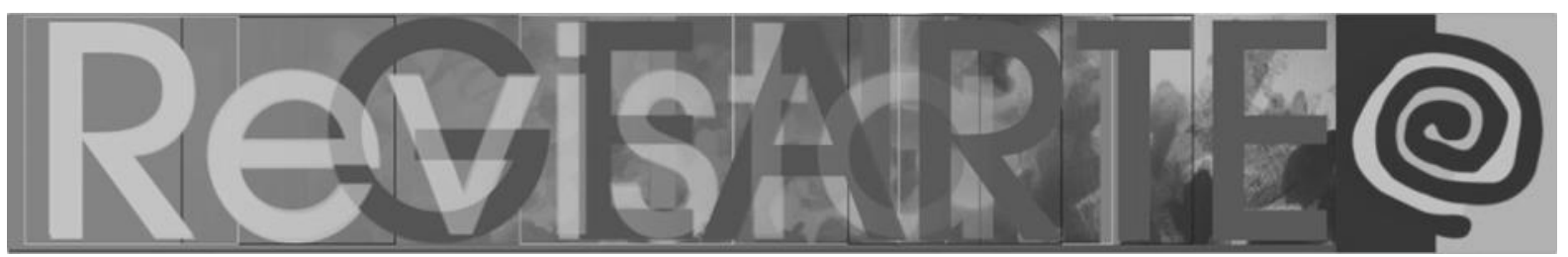

Em síntese, o texto visa refletir sobre o impacto da tecnologia sobre a vida em sociedade e o papel fundamental da educação, não somente como possibilidade de capacitação a práticas técnicas, mas, principalmente, como utilização dos novos meios para o desenvolvimento de práticas expressivas e reflexivas. Tal abordagem possibilita o entendimento da formação do arte/educador no âmbito da participação socialmente ativa, experimentando o mundo de forma significativa, interpretando os fatos cotidianos articulados à produção poética. Além disso, sob tal perspectiva as imagens são consideradas como resultantes de ações sociais de produção de sentido, simbólicas, pautadas em códigos estabelecidos pela técnica e pelos imaginários individuais e sociais.

Cabe ressaltar que privilegiamos o sentido de imaginário derivado de Gilbert Durand (2000), de um conjunto formado pelo percebido e o herdado, configurando um substrato simbólico de ampla natureza que admite as imagens na grande bacia semântica proposta por Durand. Através do imaginário, que se origina do exercício das linguagens, verbais ou não-verbais, é possível revelar e interpretar as modalidades de atuação e compreensão do ser no mundo, instaurando as diferentes formas de sentir, pensar e agir. Já sobre a produção de subjetividade, o filósofo francês Félix Guattari (1993a) corrobora afirmando a imposição coletiva de equipamentos midiáticos que forjam um modos operandi social e a necessária desestabilização dos mesmos pela transversalização de práticas que atuem como antídotos aos mecanismos controladores das instituições capitalísticas.

Em consonância com as ideias de Durand, Guattari critica a "[...] uniformização midiática e telemática, o conformismo das modas, as manipulações da opinião pela publicidade [...]" (1993a, p. 16) e propõe que a chamada ecosofia mental (da produção de subjetividade) reinvente a relação do sujeito com o corpo, a vida e a morte. Enfatiza que a maneira de operar essa produção de subjetividade se aproxime "[...] mais daquela do artista do que a dos profissionais "psi", sempre assombrados por um ideal caduco de cientificidade (GUATTARI, 1993a, p. 16). 


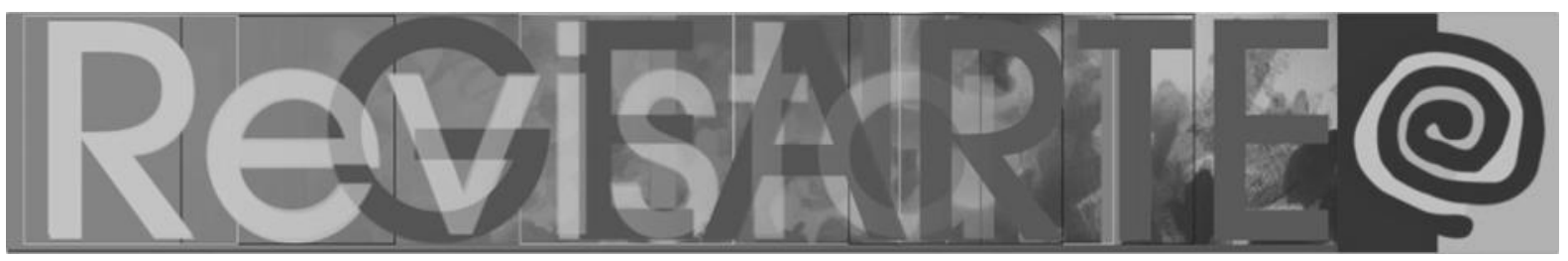

Guattari expressa, ainda, a importância de que vários profissionais, como os da Educação, estejam propondo a criação de antídotos neste processo de ressignificação. Se as tecnologias, por um lado, persuadem modos de pensar e agir, por outro elas podem ser apropriadas por meio das Artes para que os sujeitos sejam produtores de seus próprios discursos e não apenas meros reprodutores dos estereótipos culturais. Sendo assim, é cada vez mais necessária a tomada de consciência das inter-relações humanas com os meios tecnológicos para que, de fato, os usemos como meios no horizonte ético, criando maneiras de mediações pautadas em valores solidários e de cuidado à vida em sua multiplicidade.

\section{Enredamentos entre Fotografia, Imaginário e Formação Docente}

Para aprender a pensar reflexivamente é preciso aprender a observar. Entretanto, ainda encontramos muitos ambientes educativos que, diferente de estimular a observação do mundo, priorizam práticas alijadas da vida cotidiana. Para muitos professores "observar" se refere à leitura e repetição de ideias, multiplicação mecânica de conteúdos descontextualizados. Diferente disso, a cada dia fica mais clara a importância da observação do mundo ao redor como algo que instiga a imaginação e o raciocínio lógico.

Sob esse ponto de vista, estimular a sagacidade na apreensão do real, fazendo com que os estudantes foquem seu interesse nas questões que efetivamente 0 afetam, potencializa as ações pedagógicas como atitudes anti-domesticadoras, gerando posicionamentos críticos e (trans)formadores, como pregava Paulo Freire. E isso precisa ser efetivado no contexto da visualidade contemporânea e na decodificação de mensagens não-verbais, pois a realidade imagética que nos circunda expõe a necessidade de sensibilizarmos as novas gerações para a influência das imagens na vida em sociedade.

A dinâmica de transformação dos modos instituídos de existência, num tempo de infinitas possibilidades técnicas de produção e circulação de imagens, traz em si o desafio da decodificação das mensagens. Nesse âmbito, o enfoque antropológico na 


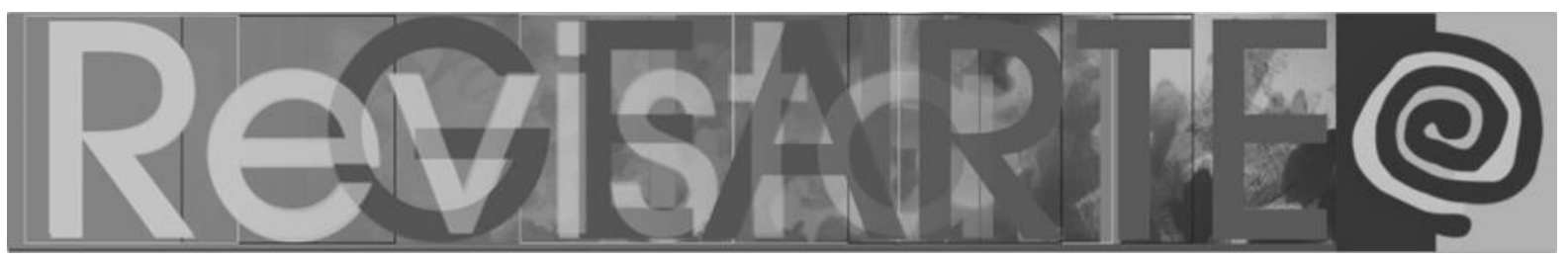

análise de imagens fotográficas por meio de abordagens focadas na dimensão simbólica da visualidade, agrega a fazeres técnicos perspectivas pedagógicas e sociológicas diferenciadas. Salienta-se também que o exercício da imaginação criadora possibilita o enfrentamento da proliferação de clichês e a ausência de pensamento crítico e reflexivo, gerando estratégias educativas em artes visuais que ultrapassam a banalização das imagens na contemporaneidade.

A imaginação, como uma vertente produtora de significados, coloca em movimento as imagens, conferindo vida a projetos utópicos e simbólicos, que delas emergem. A inovação semântica que o exercício de linguagens não-verbais proporciona, dá visibilidade a interpretação hermenêutica dos símbolos que emergem dessas imagens poéticas, enfatizando o pensamento, não a realidade. Assim, podemos considerar tais imagens como enunciações metafóricas que possibilitam a abertura a novos espaços de significação, relacionando o discurso poético a uma força heurística ontológica.

A explosão da "civilização da imagem" (DURAND, 2000) através da produção obsessiva de imagens dispersa o entendimento das mensagens, pois muitas vezes elas são ignoradas enquanto discursos não-verbais. Tal entendimento demonstra a importância da formação de espectadores/leitores capacitados à leitura crítica das imagens, visto que a aceitação tácita da instância visual pode obliterar progressivamente a nossa percepção do contexto social, político e histórico.

Lucrécia Ferrara (2002) destaca a maciça presença de textos não-verbais no cotidiano das cidades, porém, ao contrário dos verbais, o não-verbal é uma mistura de todos os códigos, até mesmo o verbal, neste caso sem função determinante. A cidade está repleta de textos não-verbais, que se mostram nos mais variados lugares, assumindo as mais diferentes formas. E para que sejam notados, eles exigem uma atenção intencional a eles direcionada, pois somente assim serão percebidos pelos espectadores/transeuntes como fruto do exercício de linguagens comunicativas nãoverbais, imagéticas. 


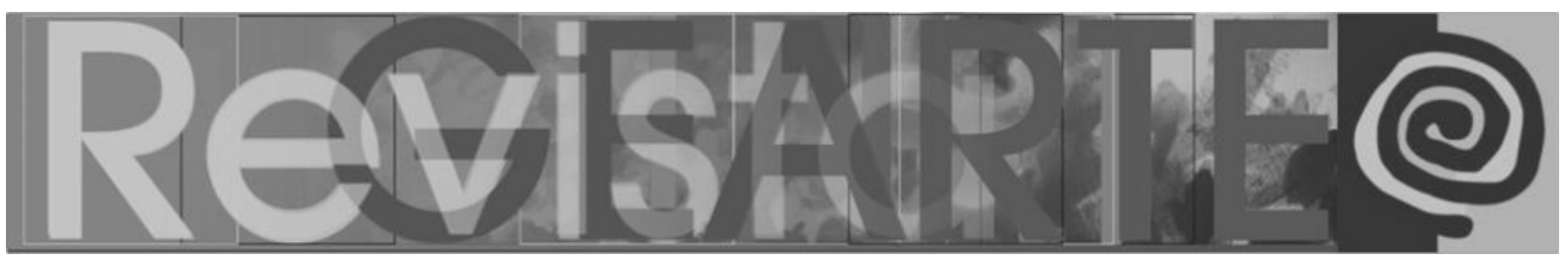

Percebe-se, portanto, que no contexto da "anestesia da criatividade imaginária" problematizada por Gilbert Durand (2000, p. 36), é fundamental estar atento a essas figuras que habitam o cotidiano contemporâneo, tanto no âmbito público como no privado. E tal conjuntura nos convoca a refletir sobre a fotografia como um recurso de representação das pessoas e dos seus percursos (auto)biográficos, e, principalmente, de criação e acumulação de conhecimentos produzidos sobre os sujeitos/fotógrafos e seus imaginários.

E é no contexto de tais reflexões que as imagens fotográficas são consideradas neste texto, dotadas assim da capacidade de abrangerem em si experiências posteriores aportadas no passado:

(...) as fotografias se constituem em construções discursivas que precisam ser lidas, cotejadas e decodificadas. No final, o que vemos não é nem a fotografia em sua inércia, nem a realidade aprisionada no plano do papel sensível; é, sim, a imagem fotográfica traduzida nos termos de nossa própria experiência. Elas se encontram em algum lugar entre as percepções, entre o que lembramos e o que aprendemos, entre o vocabulário comum e um feito por arquétipos ancestrais (BRANDÃO, 2012, p. 40).

Frente a essa realidade, no que se refere à formação de arte/educadores destaca-se a importância de estimular processos (auto)formativos vinculando significativamente a fotografia com a discussão acerca da responsabilidade social e histórica e o desenvolvimento integral dos sujeitos (GUATTARI, 1993a). E tais processos podem ser estimulados através de recursos tecnológicos, dos mais complexos aos mais simples/comuns, assim como o livro ou o quadro negro. Isso, pois o desenvolvimento de práticas voltadas às vivências da cultura urbana e seus cotidianos, refere-se também à incorporação dos recursos tecnológicos ao cotidiano educacional, dentre os quais se destaca os equipamentos fotográficos, geralmente acoplados aos celulares, item comum à maioria das pessoas.

Toda a tecnologia produz imaginário, entretanto, quando são referidas as "tecnologias do imaginário" (SILVA, 2006) isso está relacionado à utilização dos dispositivos com vistas à produção de visões simbólicas de mundo. A utilização dos equipamentos/tecnologias está cada vez mais voltada para os próprios automatismos 




técnicos, entretanto, a proposta de Juremir Machado da Silva visa subverter essas práticas utilitaristas, transformando os meios técnicos em recursos para a efetivação de experiências significativas de produção de sentido. Trata-se, portanto, de considerar as "tecnologias do imaginário" como dispositivos de produção de visões de mundo, mecanismos imaginativos usados para a sujeição de indivíduos sem destinatário, estratégias de cristalização do simbólico, das imagens e do afetivo, estimuladores de ações e dos sentidos.

É impossível negarmos o avanço tecnológico atingido pelas câmeras fotográficas nas últimas décadas, porém, não podemos esquecer que todas continuam baseando-se num princípio que remonta à Antiguidade: - controlar a luz para registrar o instante fugidio. Se o resultado do uso desses equipamentos advém de pixels ou da sensibilização de sais de prata não importa, o que se destaca é que a imagem fotográfica resulta de escolhas de quem fotografa, assim como uma escrita efetivada pela luz.

Para que as/os leitores possam melhor entender a discussão entabulada até aqui, trago um exemplo de práticas desenvolvidas com acadêmicos do curso de Artes Visuais - Licenciatura (Centro de Artes/UFPel), que futuramente estarão com seus estudantes discutindo e produzindo imagens na educação básica. Solicitei a reflexão acerca da educação em nosso país, que deveria ser pautada por duas questões principais: a escola que temos e a escola que queremos, questões essas contempladas por respostas imagéticas. Ou seja, cada um deveria refletir sobre as questões e registrar fotografias que simbolicamente contemplassem a problematização proposta (Figuras 1 e 2). 


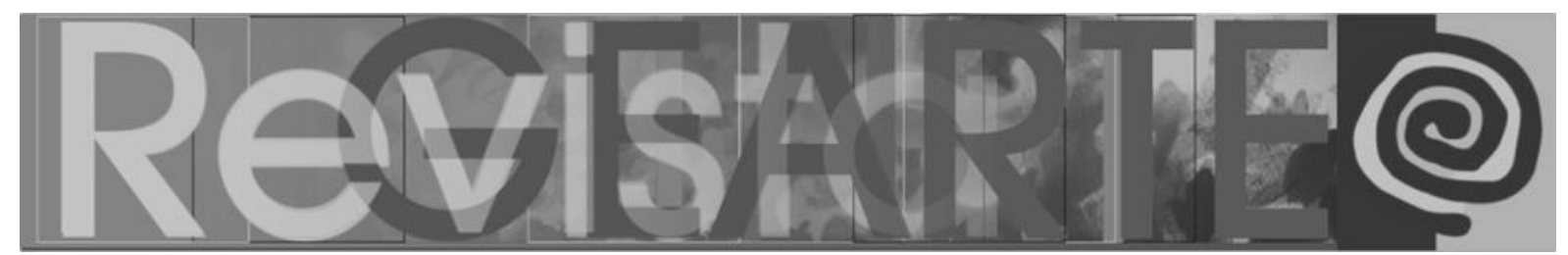

Figura 1 - A educação que temos

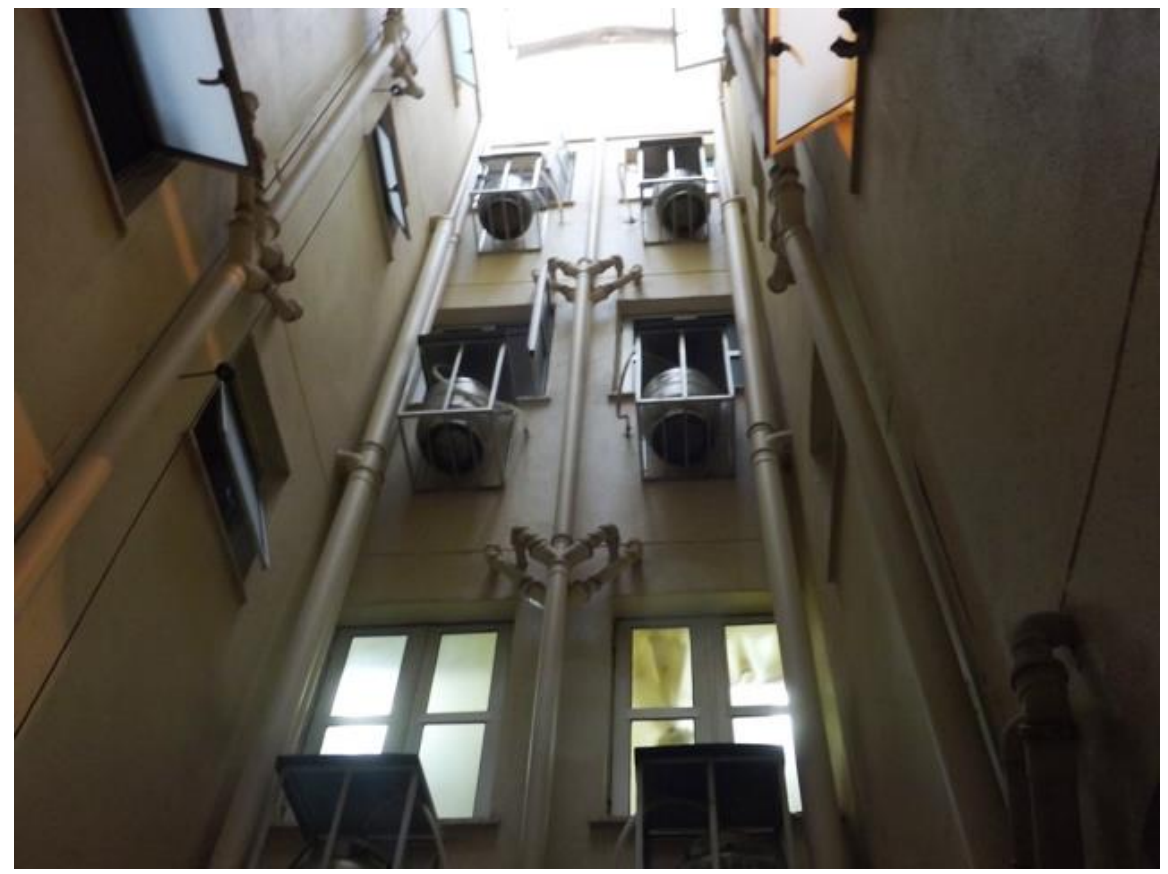

Fonte: Fotografia de Camila de Souza, 2012.

Figura 2 - A educação que queremos

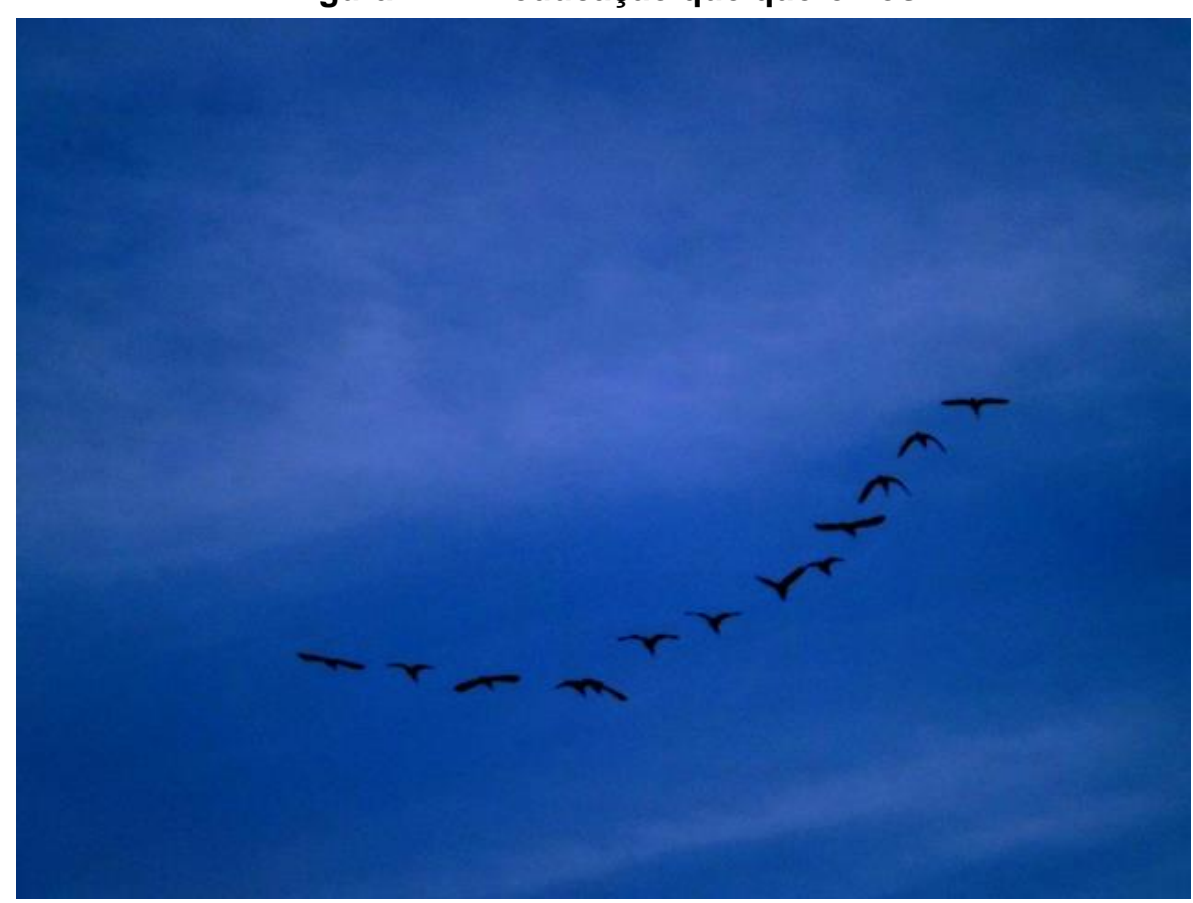

Fonte: Fotografia de Camila de Souza, 2012.

Sobre as suas escolhas Camila argumentou: "Temos uma educação engarrafada, delimitada, sistematizada e sem liberdade e autonomia. Queremos uma 


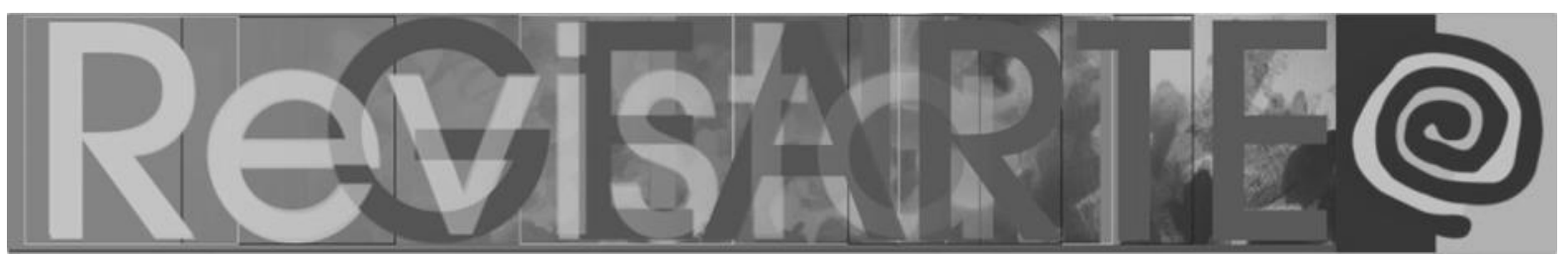

educação livre, porém acompanhada, onde um ajude o outro para que as coisas funcionem". Como é possível constatar, a riqueza argumentativa que emerge de tais exercícios, com base na utilização de "tecnologias do imaginário", possibilita abordagens discursivas que ampliam os sentidos daquilo que é mostrado, visto que as imagens instigam diferentes interpretações complementares. E isso se comprova através da declaração de outra acadêmica sobre as imagens de Camila:

\begin{abstract}
Gostei muito das imagens da Camila. Acho que de forma geral todas as imagens e conceitos sobre a educação que temos e a que queremos se completam, poderíamos formar um grande conceito, pois quando fizemos a imagem nós sintetizamos a ideia e agora que vejo a dos colegas percebo que concordo com a maioria delas (Francine Silva).
\end{abstract}

Através desse exemplo é possível avaliarmos que tais práticas, privilegiando manifestações não-verbais, são importantes propulsores de processos relacionados à educação estética, instigando a produção de imagens acompanhada de processos reflexivos. Em especial essas imagens agem como dispositivos que estimulam o sonho, a imaginação, reflexões e produções poéticas, a partir do repertório simbólico interior (mental) e do exterior (o ambiente), sobre instigações que trazem à tona um movimento de pensamentos e discussões internas a cada indivíduo.

O imaginário nos faz criar perspectivas de vida diferentemente das impostas pela cultura dominante, como um novo caminho que nos permite transgredir o que nos é imposto. As teorias de Gilbert Durand possibilitam o entendimento de que os conteúdos do imaginário não podem ser lidos desde a racionalidade clássica e ortodoxa, mas sim na perspectiva de uma "hermenêutica instauradora" que amplifica os sentidos da coisa percebida/registrada. E nesse contexto, a fotografia se destaca como uma mensagem metafórica que veicula um significado organizado, segundo as regras da produção de sentido de uma linguagem não-verbal, produzidas através de "tecnologias do imaginário".

Esse processo exige uma compreensão ampla do mundo e das relações humanas, demandando diálogos diferenciados dos tradicionalmente instituídos, que nos remetam para além da racionalidade científica herdada do Renascimento, para a 


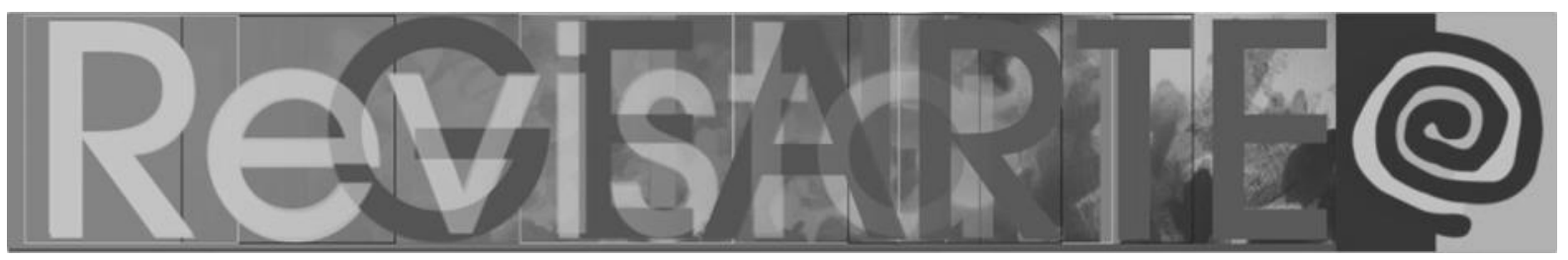

qual o real é o "mundo da matemática" acessado pelo intelecto e a realidade sensorial é ilusória. Destaca-se, portanto, a necessidade de estimularmos o desenvolvimento de diferentes formas de "ler o mundo", extrapolando o universo do verbal e da concretude aparente. Isso para que possamos estimular o desenvolvimento de sensibilidades despertas e dispostas a problematizarem os estilos de vida, suas formas e funcionamentos.

Com a utilização das "tecnologias do imaginário" todos têm as mesmas possibilidades de produção, indistintamente, entendendo a gênese das imagens e democratizando a construção do conhecimento de modo experiencial. Elas nos convocam a refletir sobre o conceito de imagem e os seus processos de geração, rompendo com a linearidade dos processos digitais contemporâneos em busca do sonho e do devaneio poético. Parâmetros, esses, alijados da realidade do ensino das Artes Visuais num número considerável de instituições escolares. Assim sendo, fica explícita a contribuição das "tecnologias do imaginário" para o desenvolvimento de novos olhares traduzidos em fotografias que frutificam da curiosidade e do imaginário de sujeitos em interação com o mundo.

\section{Possibilidades entre a produção de subjetividade e o audiovisual para práticas docentes em Artes Visuais}

Após a intersecção entre fotografia e o imaginário dos sujeitos contemporâneos retomamos a problemática de Durand (2000) sobre a "anestesia da criatividade imaginária", agora na perspectiva de estratégias pedagógicas para a promoção da criatividade por meio de tecnologias audiovisuais.

Pensar as artes visuais por meio das tecnologias contemporâneas com recursos visuais e audiovisuais é não negligenciar a necessária educação do olhar que, como "[...] educação demanda compatibilizar imagens do cotidiano a estudos estéticos sobre arte e cultura. Mas demanda, acima de tudo, o resgate da arte do fazer, que é, igualmente, uma arte do intervir, numa dada materialidade e num dado campo semântico" (MEIRA, 2006, p. 132). 


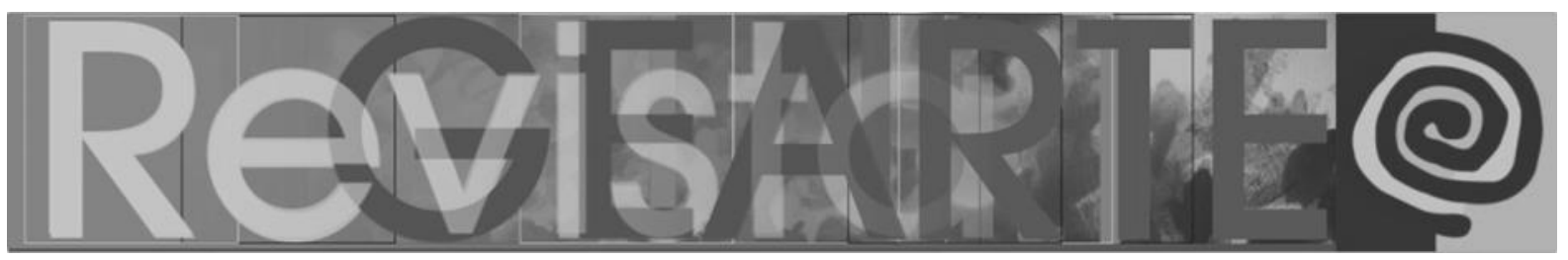

Tal intervenção se afina com os antídotos propostos por Guattari quando do uso das próprias tecnologias como estratégia de produção de subjetividades prenhes de valores de cuidado e solidariedade para construção de outros mundos possíveis. Em um universo incessante de aplicativos digitais, redes sociais e likes, o contexto pedagógico das Artes Visuais tem muito a contribuir em direção a novos modos de apropriação das redes e suas aplicações.

A série Black mirror ${ }^{1}$ apresenta um panorama doentio em que a humanidade vira refém de suas próprias tecnologias. Parece um presságio aterrorizador, mas no atual contexto histórico já vem acontecendo de algumas maneiras. Podemos verificar nas fake news uma cultura visual oportunista e manipuladora que ganha potencialidade com os dispositivos móveis de comunicação e promovem uma subjetividade nefasta e alienada.

$\mathrm{Na}$ contemporaneidade se faz imperativo que o professor assuma um papel político em seu fazer, o que, em síntese, enunciamos como compromisso para promoção de pensamentos e práticas livres de dogmas, e que se façam ética e esteticamente vetores de justiça e solidariedade. Isso impacta, como afirma Marly Meira (2006), direta ou indiretamente no plano de valores e atitudes dos estudantes e repercute no "exercício crítico e sensível do fazer artístico, seja ele em nível de percepção e imaginação, seja ele em nível de experiência prática" (MEIRA, 2006, p. 137). Tais exercícios são promotores de criatividade, o que está relacionado com a produção de subjetividade que, para Suely Rolnik, é "o perfil de um modo de ser - de pensar, de agir, de sonhar, de amar, etc. - que recorta o espaço, formando um interior e um exterior" (s/d, p. 1). Um modo de ser que pode estar precedido de um pensamento consciente, inconsciente ou de ambos, como afirmou Jun Okamoto (1999).

Série de ficção científica que narra um futuro próximo onde a natureza humana e a tecnologia de ponta entram em um perigoso conflito. Disponível em: https://www.netflix.com/br/title/70264888 Acesso em: 06 fev. 2019. 


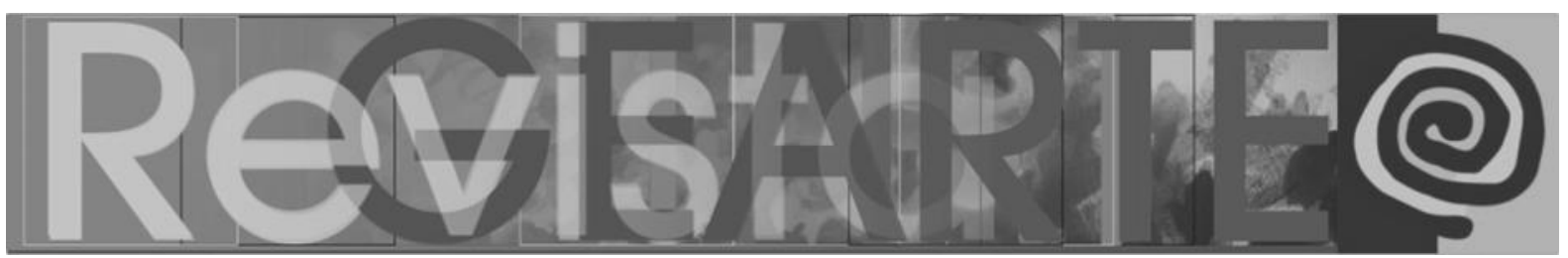

Assim, podemos verificar que a subjetividade está relacionada a um "fenômeno do comportamento humano, como resultado da interação do homem com o meio ambiente e com as relações interpessoais" (OKAMOTO, 1999, p. 12). De nossa perspectiva ecosófica (GUATTARI, 1993a), complementamos esta afirmação acrescentando a relação humana na instância mental, quando neste processo de subjetividade nos encontramos com nosso próprio interior, nossas elucubrações, desejos, afetos e memórias.

Joaquín Rodriguez Nebot (1994, p. 16) afirma que:

la subjetividad fluye a distintas velocidades, no empieza ni termina, es un continuo que se transforma y que incansablemente se transmuta. La subjetividad es lo esencialmente humano por excelencia, adquiere formas singulares y plurales. Es social y es singular en su máxima expresión. Es la base de la conformación de los imaginarios sociales, de los instituidos y potencia los niveles instituyentes.

Ela está, portanto, na base do instituído e do instituinte:

A subjetividade está em circulação nos conjuntos sociais de diferentes tamanhos: ela é essencialmente social e assumida e vivida por indivíduos em suas existências particulares. O modo pelo qual os indivíduos vivem essa subjetividade oscila entre dois extremos: uma relação de alienação e opressão, na qual o indivíduo se submete à subjetividade tal como a recebe, ou uma relação de expressão e de criação, na qual o indivíduo se reapropria dos componentes da subjetividade (GUATTARI; ROLNIK, 2005, p. 42).

Assim, a subjetividade pode produzir nos indivíduos tanto estágios de alienação como de criação. O primeiro está à mercê, por exemplo, da indústria cultural e suas investidas na homogeneização social, dos sujeitos-objetos regidos pela lei do consumo. E é o que vem acontecendo, visto que "A subjetividade permanece hoje massivamente controlada por dispositivos de poder e de saber que colocam as inovações técnicas, científicas e artísticas a serviço das mais retrógradas figuras da socialidade" (GUATTARI, 1993b, 190-191). Essas figuras a que Guattari se refere estão relacionadas ao instituído, ao conservado. E a mídia, como meio de comunicação e produção de informações, é intensamente usada para esses 


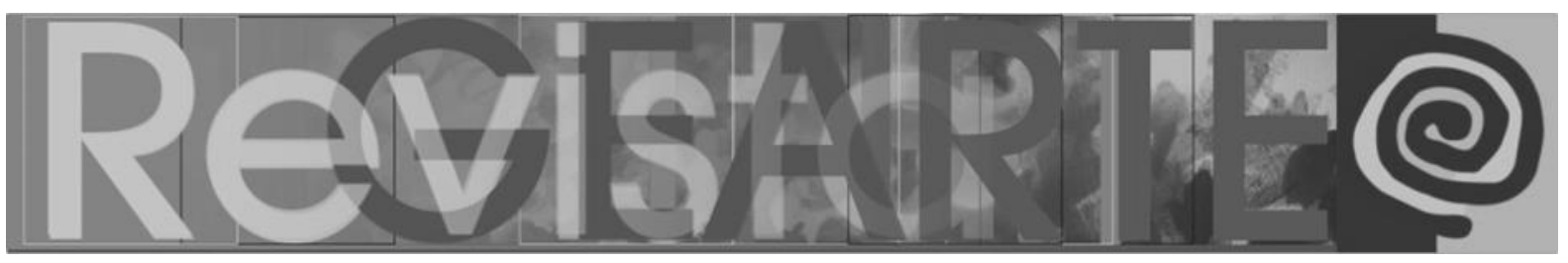

mecanismos de controle e poder, configurando o que podemos considerar uma subjetividade dominante.

Corroborando, Guattari enfatiza que "as máquinas tecnológicas de informação e de comunicação operam no núcleo da subjetividade humana, não apenas no seio das suas memórias, da sua inteligência, mas também da sua sensibilidade, dos seus afetos [...]" (1992, p. 14). Daí a importância pedagógica no campo das Artes Visuais para com os automatismos maquínicos produzidos nas interfaces midiáticas da cultura visual, por meio da internet e dos dispositivos móveis de comunicação.

Percebe-se que nosso tempo histórico está repleto de instrumentos tecnológicos capazes de gerar, reter e emitir informações produtoras de subjetividade. Nesse contexto, é clara a existência da indústria cultural interessada em estimular o consumo por meio das ferramentas tecnológicas que produzem tais significações de maneira massificadora, pois:

Os produtos culturais, os filmes, os programas radiofônicos, as revistas ilustram a mesma racionalidade técnica, o mesmo esquema de organização e de planejamento administrativo que a fabricação de automóveis em série ou os projetos de urbanismo (MATTELART, 2003, p. 77).

Como disse o crítico de arte Pierre Restany (1978), em seu "Manifesto do Rio Negro", perceber nosso tempo ecológico é "lutar muito mais contra a poluição subjetiva do que contra a poluição objetiva - a poluição dos sentidos e do cérebro contra a queda do ar e da água". Essa poluição tende a acontecer por diversos motivos, como, por exemplo, patológicos e o desejo de poder.

As Artes Visuais na educação pode ser um viés problematizador sobre este tipo de poluente instituído pelas tecnologias da comunicação. Pois, afinal, ao serem socialmente construídas é necessário pensar estratégias instituintes de apropriação dessas mídias telemáticas. Nesse caminho poderemos repensar nossos hábitos para uma permanente transformação ecosófica. 


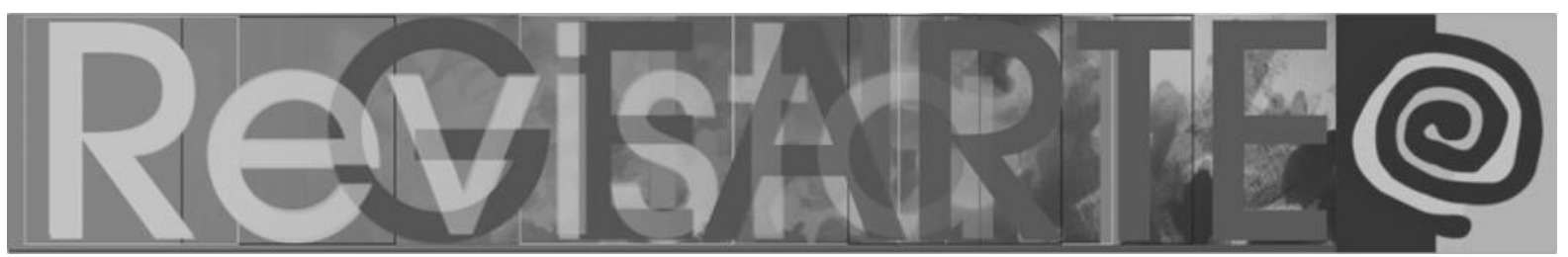

Uma alternativa metodológica como antídoto audiovisual neste sentido é o uso de vídeo-mensagem². Este recurso pedagógico consiste em propor troca de mensagens de vídeo entre os alunos como exercício audiovisual. Seguindo alguns critérios pré-estabelecidos como, por exemplo, estipular o tempo de um minuto como duração máxima por mensagem; não falar enquanto realiza o vídeo, preservando a atmosfera sonora do ambiente e não sustentando a produção em uma mensagem falada. Após um da dupla receber a mensagem deve procurar responde-la a partir dos mesmos critérios iniciais. É indicado que não haja diálogo entre cada dupla sobre o que criaram. A análise coletiva das vídeo-mensagens deve ser feita entre o grupo para estimular reflexões e debates que propiciem a tomada de consciência das atmosferas sonoras que constituem os lugares de produção, bem como os diálogos visuais resultantes das trocas. Discutir o caráter indicial dos trabalhos e os múltiplos olhares possíveis pode amplificar e aprofundar leituras culturais mais críticas, desnaturalizando a subjetividade (BOURRIAUD, 2009) no fluxo da produção do imaginário e de um olhar sensível:

O computador e a câmera de vídeo delimitam possibilidades de produção, as quais dependem das condições gerais da produção social, das relações concretas existentes entre os Homens: a partir daí, os artistas inventam modos de vida ou tornam consciente um determinado momento $\mathrm{M}$ da linha de montagem dos comportamentos sociais, permitindo-nos imaginar um outro estado de nossa civilização (BOURRIAUD, 2009, p. 99).

Proposições pedagógicas como o vídeo-mensagem nos permitem imaginar outro estado de civilização, com maior tomada de consciência crítica e sensível sobre os modos de produção e seus próprios protagonismos históricos. Além disso, tais exercícios podem vir acompanhados da leitura de produtos audiovisuais como, por exemplo, a já citada série Black mirror. Pois, tanto a busca por likes como as fake news são acionadas pelos mesmos mecanismos de controle apresentados na série, os quais penetram nossas subjetividades na mesma medida avassaladora que

2 Este exercício, por mim desenvolvido (Cláudio) na disciplina "Ateliê de Artes do Vídeo" da UFPel, proporciona aos estudantes múltiplas leituras das produções audiovisuais realizadas pelo grupo, o que promove novos olhares sobre si e os colegas estimulando a desnaturalização da subjetividade. 




determina as tomadas de decisões sociais que influenciam nossos modos de viver e de se relacionar.

O exercício de múltiplos perspectivismos coloca em xeque o nosso próprio entendimento sobre nossa visão de mundo, podendo, por meio de debate e reflexão, ampliar nossa consciência sobre o audiovisual produzido. O questionamento sobre as fake news é fundamental para a ampliação de consciência histórica em direção a pensamentos e práticas mais livres, na contramão dos regimes totalitários. Por isso, se faz fundamental as Artes Visuais no ensino público e privado como alternativa frente a mudança na forma de percepção inaugurada pelo universo audiovisual digital e seus dispositivos móveis de circulação.

\section{Considerações finais}

Por muito tempo o conhecimento esteve enredado nas malhas hegemônicas das linguagens verbais, de modo que o domínio de ambos coincidia. Com a multiplicidade dos sistemas sígnicos, com seus cruzamentos e códigos, como consequência da evolução tecnológica, é praticamente impossível circunscrever o conhecimento ao domínio de qualquer linguagem. Aqui começa a expressão do imaginário humano, e ele floresce das linguagens verbais e não-verbais que nos possibilitam a leitura de um mundo que emerge do conjunto de experiências sociais e individuais, da constelação de textos que viabilizam a circulação dos sentidos e dos saberes humanos.

Intervir em prol de ações micropolíticas para apropriação das tecnologias contemporâneas é fundamental para que seja possível "[...] aprender a 'captar, enriquecer e reinventar' a subjetividade, sob pena de vê-la se transformar numa aparelhagem coletiva rígida a serviço exclusivo do poder" (BOURRIAUD, 2009, p. 125). Assim, por meio de Durand e Guattari, respectivamente nas pistas do imaginário e da produção de subjetividade, chegamos ao desejo de uma formação da vida cultural através da ação criativa. Através das Artes Visuais e das tecnologias contemporâneas, professores e artistas podem promover novas subjetividades, a 


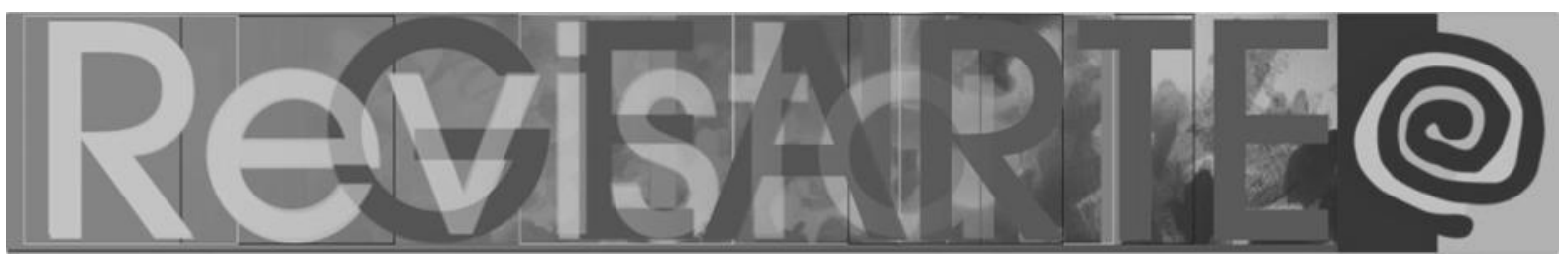

produção de novos sentidos e subverter os automatismos maquínicos, promovendo outros modos culturais diferenciados e desnaturalizados.

Consideramos, também, ser de suma importância agregar as produções em Fotografia e Vídeo à reflexão acerca das possibilidades das Artes Visuais no âmbito da Educação Básica, instigando ponderações e ações que favoreçam a análise das transformações do mundo urbano contemporâneo e de suas respectivas representações. Como a nossa intenção é estimular o desenvolvimento de novos pensamentos, pluralistas e interativos, o desafio configura-se na criação de ambientes nos quais os sujeitos sejam capazes de questionar, refletir, assumir valores e, principalmente, exercitarem a autocrítica e a imaginação no intuito de transformar criativamente mentalidades e comportamentos.

\section{Referências}

BOURRIAUD, Nicolas. Estética relacional. São Paulo: Martins Fontes, 2009.

BRANDÃO, Cláudia Mariza Mattos. Entre photos, graphias, imaginários e memórias: a (re)invenção do ser professor. 2012. 154f. Tese (Doutorado) - Programa de Pós-Graduação em Educação. Universidade Federal de Pelotas, Pelotas. Disponível em: http://repositorio.ufpel.edu.br:8080/bitstream/123456789/1678/1/Claudia\%20Mariza\%20Mattos\%20Br andao_Tese.pdf

COUCHOT, Edmont. A tecnologia na arte: da fotografia à realidade virtual. Porto Alegre: Editora da UFRGS, 2003.

DURAND, Gilbert. A imaginação simbólica. Lisboa, Portugal: Edições 70, 2000.

FERRARA, Lucrécia D'Aléssio. Leitura sem palavras. São Paulo, Ática, 2002.

GUATTARI, Félix. Caosmose. São Paulo: Ed. 34, 1992.

GUATTARI, Félix. As três ecologias. Campinas: Papirus, 1993a.

GUATTARI, Félix. Da produção de subjetividade. In: PARENTE, André (Org.). Imagem-máquina: a era das tecnologias do virtual. Rio de Janeiro: Ed. 34, 1993b. cap. 16, p. 177-191.

GUATTARI, Félix; ROLNIK, Suely. Micropolítica: cartografias do desejo. Petrópolis: Vozes, 2005.

LÓPEZ Quintás, Alfonso. Estética. Petrópolis, RJ: Vozes, 1992.

MATTELART, Armand; MATTELART, Michèle. História das teorias da comunicação. São Paulo: Loyola, 2003.

MEIRA, Marly Ribeiro. Educação estética, arte e cultura do cotidiano. In.: PILLAR, Analice Dutra (org.). A educação do olhar no ensino das artes. Porto Alegre: Mediação, 2006.

NEBOT, Joaquín Rodriguez. Multiplicidad y subjetividad. Montevideo: Nordan Comunidad, 1994.

OKAMOTO, Jun. Percepção ambiental e comportamento. São Paulo: Plêiade, 1999. 


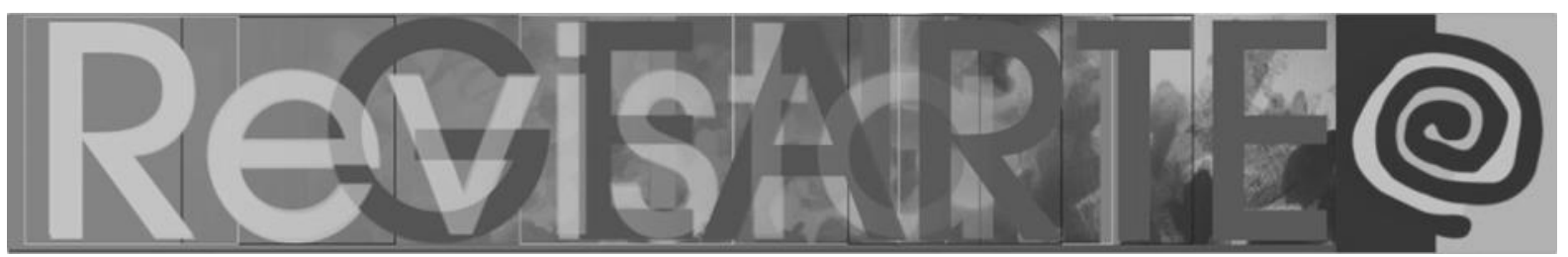

RESTANY, Pierre. O manifesto do Rio Negro. Alto Rio Negro, 3 de agosto em 1978. Disponível em: https://www.ufmg.br/revistaufmg/downloads/21/13_pag260a277_fabriciofernandino_franskrajcberg.pdf Acesso em: 28 jan. 2019.

ROLNIK, Suely. Uma insólita viagem à subjetividade: fronteiras com a ética e a cultura, s/d. Disponível em: http://caosmose.net/suelyrolnik/pdf/subjeticabourdieu.pdf Acesso em: 13 jan. 2019.

SILVA, Juremir Machado da. As tecnologias do imaginário. $2^{\mathrm{a}}$ ed. Porto Alegre: Editora Sulina, 2006.

\section{Cláudia Mariza Mattos Brandão}

Professora do Centro de Artes/Artes Visuais - Licenciatura, da Universidade Federal de Pelotas/UFPel (RS, Brasil). Doutora em Educação (UFPel, 2012), Mestre em Educação Ambiental pela Universidade Federal do Rio Grande/FURG (2003), Especialista em Artes e Educação Física na Educação Básica pela Universidade Federal do Rio Grande do Sul/UFRGS (2008), graduada em Artes Visuais (FURG, 1996) e Engenharia Civil (FURG/1980). Atua no PPG Mestrado em Artes Visuais Cearte/UFPel, e no curso de Especialização em Artes: Ensino e Percursos Poéticos (CA/UFPel). É líder do PHOTOGRAPHEIN - Núcleo de Pesquisa em Fotografia e Educação (UFPel/CNPq), pesquisadora do ARTE, ECOLOGIA E SAUDE (UFPel/CNPq) e do NEMEC - Núcleo de Estudos em Memória e Cultura (UPF/CNPq). É pesquisadora da área da Fotografia e das teorias do Imaginário, com ênfase nas narrativas (auto)biográficas poéticas/simbólicas. Como artista visual já participou de várias exposições coletivas, nacionais e internacionais, apresentando seis exposições individuais. Desenvolve, principalmente, os seguintes temas: Artes Visuais, Fotografia, Educação Ambiental e Formação Docente.

E-mail: attos@vetorial.net

Currículo: http://lattes.cnpq.br/4898554772122279

\section{Cláudio Tarouco de Azevedo}

Professor do Centro de Artes, Artes Visuais - Licenciatura, da Universidade Federal de Pelotas, UFPel (RS, Brasil). Pós-doutor em Artes Visuais (UFPel, 2016), Doutor em Educação Ambiental (FURG, 2013), Mestre em Educação Ambiental (FURG, 2010), graduado em Artes Visuais (FURG, 2005). Atua no PPG Mestrado em Artes Visuais CA/UFPel. É líder do Grupo de Pesquisa Arte, Ecologia e Saúde GPAES/CNPq/UFPel, pesquisador do PHOTOGRAPHEIN - Núcleo de Pesquisa em Fotografia e Educação (UFPel/CNPq). É pesquisador da área da Fotografia e Audiovisual, com ênfase na ecosofia e na produção de subjetividade. Como artista visual já participou de várias exposições coletivas, nacionais e internacionais, apresentando sete exposições individuais. Desenvolve, principalmente, os seguintes temas: Artes, Educação Ambiental, Saúde Mental, Biorrizoma.

E-mail: claudiohifi@yahoo.com.br

Currículo: http://lattes.cnpq.br/8041917371066975

Recebido em 7 de março de 2019

Aceito em 20 de abril de 2019 